\title{
4. Synthetic Biology as a Field of Dual-Use Bioethical Concern
}

\author{
Alexander Kelle
}

\section{Introduction}

Over the past decade synthetic biology has emerged as one of the most dynamic subfields of the post-genomic life sciences. According to a European high-level expert group, synthetic biology comprises 'the synthesis of complex, biologically based (or inspired) systems which display functions that do not exist in nature ... [and] is a field with enormous scope and potential'. ${ }^{1}$ Some of the areas where this expert group argues that synthetic biology could have a major impact include biomedicine, a sustainable chemical industry, environment and energy, and biomaterials. If the emerging discipline of synthetic biology can deliver on the promises of some of its leaders and become as pervasive as computing has become in the past few decades, we might very well be witnessing a fundamental shift similar to the one that happened to chemistry with the introduction of the periodic table. If synthetic biologists live up to some of the more far-reaching expectations, biology ultimately may become a mechanistic science.

On the one hand, synthetic biology developments show promise of leading to beneficial applications in a number of areas, such as drug development, ${ }^{2}$ biodegradation ${ }^{3}$ and biofuels. ${ }^{4}$ At the same time, the dual-use character of this new technoscience carries with it the possibility of synthesised biological parts, modules and systems being malignly misused. This dual-use potential has - at a rather abstract level and with a focus on one particular subfield of synthetic biology, that is, DNA synthesis - been recognised by practitioners in the field as well as analysts. While this is a positive development, however, these mostly technical governance measures that are addressing DNA synthesis capabilities need to be broadened so as to cover all aspects of synthetic biology and to allow for a comprehensive bioethical analysis of the field's dual-use implications. In addition, part of the discourse on the broader societal implication of synthetic biology can be traced back to the debates on ethical, legal and social implications

\footnotetext{
1 Synthetic Biology. Applying Engineering to Biology, Report of a New and Emerging Science and Technology (NEST) High-Level Expert Group, European Commission, Brussels, 2005, p. 5.

2 See Neumann, H. and Neumann-Staubnitz, P. 2010, 'Synthetic biology approaches in drug discovery and pharmaceutical biotechnology', Applied Microbiology and Biotechnology, vol. 87, pp. 75-86.

3 See Kirby, J. R. 2010, 'Designer bacteria degrades toxin', Nature Chemical Biology, vol. 6, pp. 398-9.

4 See Dellmonaco, C. et al. 2010, 'The path to next generation biofuels: successes and challenges in the era of synthetic biology', Microbial Cell Factories, vol. 9.
} 
(ELSI) of genetic engineering. Yet, given their limited nature, these debates do not provide a solid foundation for a comprehensive discussion and assessment of synthetic biology's dual-use potential.

This chapter will first outline the scope of synthetic biology as a new subfield in the life sciences in which different science and engineering disciplines converge. This will be followed by a brief discussion of synthetic biology's potential for malign misuse as well as some of the proposals for governance of this new technoscience. Thus far, the mostly technical character of these proposals has resulted in a rather limited appreciation of the wider governance issues related to the full breadth of approaches usually subsumed under the synthetic biology label. The final section will discuss both academic and institutional contributions to a bioethically informed discourse on the misuse potential of synthetic biology.

\section{Scope of synthetic biology as a subfield in the life sciences}

\section{Attempts at defining synthetic biology}

Not surprisingly for a discipline that is still in its formative stages, several definitions exist for synthetic biology. One that has received the most attention describes synthetic biology as 'the design and construction of new biological parts, devices, and systems, and the re-design of existing, natural biological systems for useful purposes'. ${ }^{5}$ This definition clearly reflects the approach to synthetic biology pioneered by scientists at the Massachusetts Institute of Technology (MIT), and puts centre stage the idea to develop a registry of standardised biological parts that can be assembled in devices and systems with predefined functions. Although the MIT framing of the issue area has certainly sparked the development of the whole field (for example, by organising the first international Synthetic Biology Conference in Boston in 2004, by supporting the Biobricks Foundation, and by organising the annual iGEM student competitions), an exclusive focus on the parts-based approach to synthetic biology tends to overlook other important subfields in synthetic biology (see Table 4.1 for an overview). For ease of reference, four different substrands of synthetic biology that have developed since the early years of the twenty-first century are distinguished here ${ }^{6}$

5 See <http://syntheticbiology.org/Who_we_are.html > (viewed 6 November 2008).

6 This subdivision follows Schmidt, M. 2009, 'Do I understand what I can create?' in M. Schmidt, A. Kelle, A. Ganguli-Mitra and H. de Vriend (eds), Synthetic Biology. The Technoscience and Its Societal Consequences, Springer, Dordrecht, pp. 81-100. 
- engineering DNA-based biological circuits, by using standardised biological parts

- identifying the minimal genome

- constructing protocells - in other words, living cells from base chemicals

- creating orthogonal biological systems in the laboratory through chemical synthetic biology.

Two enabling technologies also tend to be usually subsumed under the heading of synthetic biology, although they have a more supportive role to the four fields mentioned above. This applies first and foremost to the increasingly more affordable large-scale DNA-synthesis capabilities that some companies are providing, ${ }^{7}$ but also to the more generic bioinformatics capabilities utilised by those attempting to identify a minimal genome.

Thus, synthetic biology at the very least aims at merging molecular biology with engineering, by designing and producing new biological parts, devices and systems. To achieve this goal, synthetic biology utilises high-throughput commercial DNA-synthesis capabilities to provide the actual biological material for the assembly of genetic circuits. In addition, synthetic biology is relying on increasingly powerful information technology tools that allow for the modelling of certain desired biological functions.

A report by the Royal Academy of Engineering in the United Kingdom has detailed the design cycle that informs the engineering approach to synthetic biology. ${ }^{8}$ Accordingly, the design cycle for biological systems starts with an initial specification stage for bioparts, which is 'followed by a detailed design step', drawing on 'the ability to undertake detailed computer modeling'. ${ }^{9}$ In the subsequent implementation stage, synthesised DNA is usually inserted into $E$. coli, yeast or some other suitable chassis. In the final validation stage, the functionality of the original specification is verified. Standardised bioparts that have undergone such quality controls can then be utilised to build standard devices, which, in turn, can be assembled into biological systems. As O'Malley has recently pointed out, however, research and development (R\&D) in synthetic biology have so far generally not been that straightforward. Instead, strictly hypothesis-driven work is regularly complemented by '[e]xploration, iterativity and kludging'. ${ }^{10}$ In other words, realisation of the engineeringdriven and standards-based 'plug and play' ideal of many synthetic biologists still awaits realisation and will for some time.

7 See, for example, the web pages of GENEART ( $<$ www.geneart.com $>$ ) or Blue Heron ( $<$ www. blueheronbio. com>). Another prominent company in this area, Codon Devices, recently closed. See Hayden, E. C. and Ledford, H. 2009, 'A synthetic biology reality check', Nature, vol. 458, p. 818.

8 The Royal Academy of Engineering 2009, Synthetic Biology: Scope, Applications and Implications, The Royal Academy of Engineering, London, esp. pp. 18-21.

9 Ibid., p. 19.

10 O'Malley, M. 2011, 'Exploration, iterativity and kludging in synthetic biology', C. R. Chimie, vol. 14, pp. 406-12. 


\begin{tabular}{|c|c|c|c|c|}
\hline 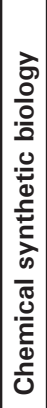 & 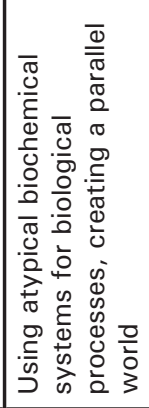 & 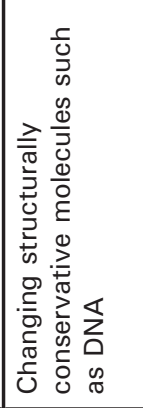 & 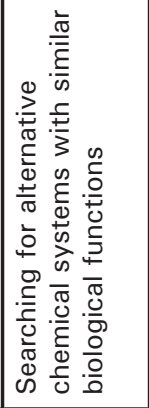 & 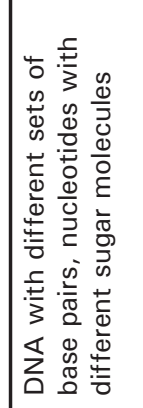 \\
\hline 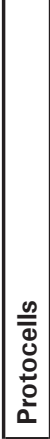 & 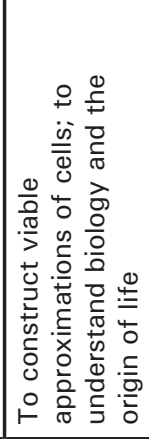 & 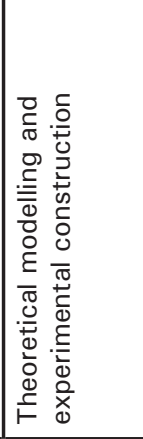 & 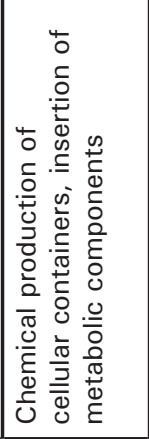 & 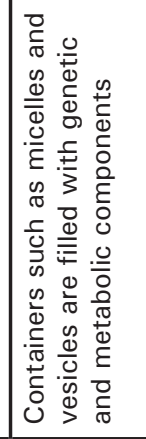 \\
\hline 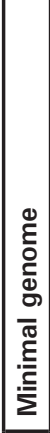 & 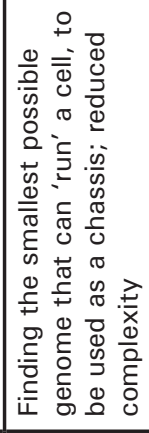 & 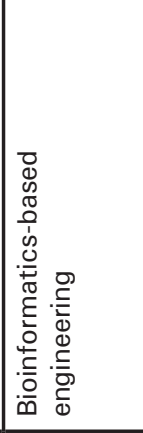 & 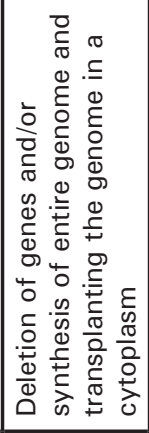 & 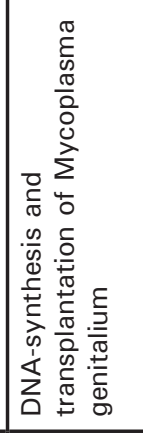 \\
\hline 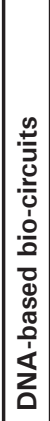 & 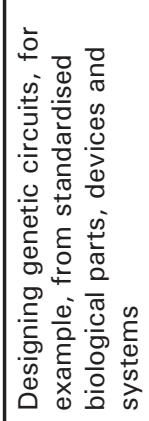 & 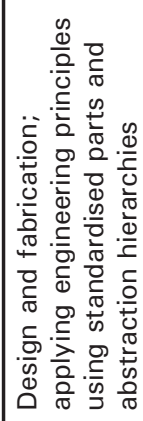 & 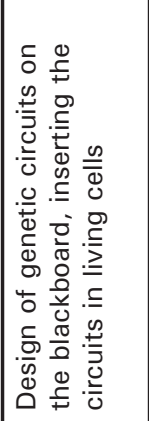 & 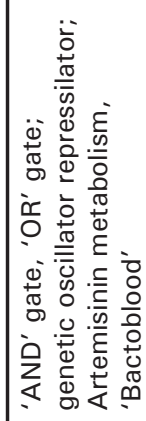 \\
\hline & 安 & 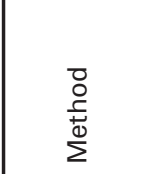 & 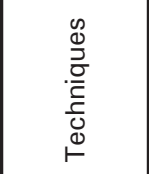 & 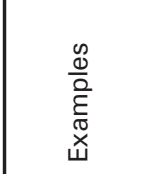 \\
\hline
\end{tabular}


According to a widely accepted historiography of the term 'synthetic biology', it entered the scientific vocabulary in 1912 with the publication of the French chemist Stephane Leduc's monograph of the same title. ${ }^{11}$ As Campos outlines, the desire among scientists to redesign life can be observed in a number of different approaches throughout the twentieth century. ${ }^{12}$

Synthetic biology in its contemporary manifestation was initially promoted under labels such as 'open source biology' and 'intentional biology', which were proposed for the renewed attempt by some to convert biology into a predictive science by incorporating elements of the engineering design cycle. As Rob Carlson, for example, stated in 2001: 'When we can successfully predict the behavior of designed biological systems, then an intentional biology will exist. With an explicit engineering component, intentional biology is the opposite of the current, very nearly random applications of biology as technology.' ${ }^{\prime 3}$ Besides the Molecular Sciences Institute of the University of California at Berkeley at which Rob Carlson was envisaging a distributed open-source biological manufacturing system driving future industry, another early institutional hub of contemporary synthetic biology was located at MIT, where in the Computer Science and Artificial Intelligence Laboratory (CSAIL) Tom Knight had set up a biology laboratory and started developing the Biobricks standard for biological parts with support from a Defense Advanced Research Projects Agency/Office of Naval Research (DARPA/ONR) contract on 'Computing with Synthetic Biology' ${ }^{14}$

The two main vehicles for developing the field of synthetic biology since then have been the annual student iGEM competition as well as the four SBx.0 conferences. While the first two of these conferences were held in the United States (Cambridge and Berkeley), SB3.0 took place in Zurich in the summer of 2007 and SB4.0 in Hong Kong in October 2008. Over the course of these SB conferences it has become obvious that synthetic biology encompasses more than only the parts-based approach emphasised here. While in this context clearly some relabelling of more traditional biotechnology and molecular biology approaches can be observed in order to participate in a newly established, 'cool' and potentially well-funded discipline, there clearly are different facets to contemporary synthetic biology that go beyond the engineering of biological parts, devices and systems. ${ }^{15}$

\footnotetext{
11 See, for example, de Lorenzo, V. and Danchin, A. 2008, 'Synthetic biology: discovering new worlds and new words', EMBO Reports, vol. 9, pp. 822-7.

12 Campos, L. 2009, 'That was the synthetic biology that was', in Schmidt et al., op. cit., pp. 5-21.

13 Carlson, R. 2001, 'Open source biology and its impact on industry', IEEE Spectrum, pp. 15-17, as quoted by Campos, op. cit., p. 17.

14 Knight, T. F. 2002, DARPA BioComp Plasmid Distribution 1.00 of Standard Biobrick Components, <http:// dspace.mit.edu/handle/1721.1/21167>.

15 For an even more detailed subdivision of the field than the one used here, see Lam, C. M. C., Godinho, M. and dos Santos, V. 2009, 'An introduction to synthetic biology', in Schmidt et al., op. cit., pp. 23-48.
} 


\section{Beneficial uses of synthetic biology}

Optimistic assessments of synthetic biology's potential, such as the one contained in the abovementioned report by an EU high-level expert group, expect it to 'drive industry, research, education and employment in the life sciences in a way that might rival the computer industry's development during the 1970s to the $1990 s^{\prime}{ }^{16}$ The same group of experts envisages synthetic biology to have such a dramatic effect by 're-organizing biotechnological development' in a way so that 'research \& development are likely to proceed in a much faster and much more organized way' ${ }^{17}$ The report identifies six areas that could benefit from such a streamlining of R\&D processes: biomedicine, synthesis of biopharmaceuticals, sustainable chemical industry, environment and energy, production of smart materials and biomaterials, and counter-bioterrorism measures. ${ }^{18}$

Probably the most often quoted example for the imminent breakthrough of a high-value synthetic biology application is related to the insertion of an engineered metabolic pathway into a yeast strain to produce artemisinic acid. ${ }^{19}$ This in turn can be converted into artemisinin, which forms the basis of antimalarial drugs. The key goal of the attempt to synthesise this artemisinin precursor is to reduce production costs for the therapy and thus increase its availability in developing regions of the world. As Chang and Keasling have pointed out in relation to 'this approach, the genes related to the biosynthetic pathway for a target natural product are transplanted from the natural host into a genetically tractable host system such as E. coli or S. cerevisiae'.$^{20}$ Similarly, synthetic biologists have made some progress in utilising genetically modified microbes to produce biofuels. ${ }^{21}$

16 Synthetic Biology, op. cit., p. 13.

17 Ibid.

18 Ibid., pp. 13-17.

19 Keasling, J. et al. 2006, 'Production of the antimalarial drug precursor artemisinic acid in engineered yeast', Nature, vol. 440, pp. 940-3, <http://www.nature.com/nature/journal/v440/n7086/abs/nature04640.html>.

20 Chang, M. C. Y. and Keasling, J. D. 2006, 'Production of isopronoid pharmaceuticals by engineered microbes', Nature Chemical Biology, < doi:10.1038/nchembio836>.

21 See, for example, Clomburg, J. M. and Gonzales, R. 2010, 'Biofuel production in Escherichia coli: the role of metabolic engineering and synthetic biology', Applied Microbiology and Biotechnology, vol. 86, pp. 419-34; Keasling, J. D. and Chou, H. 2008, 'Metabolic engineering delivers next-generation biofuels', Nature Biotechnology, vol. 26, pp. 298-9. 


\section{Synthetic biology's potential for malign misuse}

\section{Potential misapplication(s)}

The ability to understand, modify and ultimately create new life forms at the molecular level clearly represents a scientific paradigm shift with a substantial misuse potential. In general terms, synthetic biology can be misused to engineer biological parts or modules that increase the efficiency/stability/usability of known warfare agents or to synthesise new ones.

While currently there are still formidable challenges to overcome-for example, in the creation of synthetic pathogens ${ }^{22}$ - there is a general acknowledgment that these hurdles will be lowered by scientific and technological advances over the next few years. In the words of a report jointly published by MIT, the Centre for Strategic and International Studies (CSIS) and the J. Craig Venter Institute: 'In the near future, however, the risk of nefarious use will rise because of the increasing speed and capability of the technology and its widening accessibility. ${ }^{23}$ While this statement refers to the risks related to synthetic genomics, it is also applicable to the wider area of synthetic biology.

A brief look into two specific applications of major impacts expected from synthetic biology as described in the abovementioned New and Emerging Science and Technology (NEST) report — smart drugs and vectors for therapyshould suffice to illustrate the quantum leap in biological warfare or bioterrorist capabilities that may result from advances in synthetic biology. According to the NEST report, a 'smart drug includes a diagnostic module that ... is capable of directly sensing of molecular disease indicators ... it will only become active in cells affected by disease' ${ }^{24}$ The misuse potential of such smart-drug technology is obvious: if the sensing mechanism were programmed to detect other, not disease-related indicators and/or the activated chemical compound were to harm, not cure or would simply be administered in the wrong dosage, considerable harm could be done with such a device. Similarly, it is conceivable that newly designed or modified viral vectors that can 'deliver healthy genes to the target tissue' or that 'can recognize specific cells and target them for

\footnotetext{
22 See Epstein, G. L. 2008, 'The challenges of developing synthetic pathogens', Bulletin of the Atomic Scientists, vol. 64, pp. 46-7.

23 Garfinkel, M. S., Endy, D., Epstein, G. L. and Friedmann, R. M. 2007, Synthetic Genomics: Options for Governance, <http://www.jcvi.org/cms/fileadmin/site/research/projects/synthetic-genomics-report/ synthetic-genomics-report.pdf $>$, p. 12.

24 Synthetic Biology, op. cit., p. 14.
} 
destruction ${ }^{25}$ could be easily diverted from their intended benign use to malign applications that would, for example, aim at delivering pathogenic genes or target not cancer, but nerve or other essential cells.

\section{Recognition of dual-use concerns}

In parallel with the focus of early activities in synthetic biology in general, which have been concentrated in the United States, the origins of the discourse on preventing the misuse of this new field of scientific inquiry also can be traced back to the US scientific and policymaking communities. In 2004, for example, George Church put forward 'A Synthetic Biohazard Non-Proliferation Proposal' to address some of the biosecurity concerns of synthetic biology. The underlying rationale for this proposal was his identification of the misuse of synthetic biology as a low-probability, high-consequence event. ${ }^{26}$ At around the same time, the first big synthetic biology gathering, SB1.0 at the MIT, also included a couple of presentations on safety, security and ethical issues related to synthetic biology. Echoing Church's assessment of the misuse of synthetic biology as a lowprobability, high-consequence event, George Poste of the Biodesign Institute at Arizona State University also made reference to the move away from the 'bug' towards 'biological circuit disruptors' as the object of concern. ${ }^{27}$ At the Second International Conference on Synthetic Biology, the third day of the conference was dedicated to four key societal issues associated with synthetic biology, one of which was 'biosecurity and risk'. ${ }^{28}$ Discussions during the corresponding session were informed by the preparatory work undertaken by the Berkeley SynBio Policy Group, which had produced a white paper on 'Community-Based Options for Improving Safety and Security in Synthetic Biology' ${ }^{29}$

Also in 2006 the National Research Council tasked a Committee on Advances in Technology and the Prevention of their Application to Next Generation Biowarfare Threats to analyse the impact of the revolution in the life sciences on the evolving biosecurity threat spectrum. ${ }^{30}$ In dispensing of its task, this committee rejected a list-based approach, for which it felt that, because of 'the pace of research discovery in the life sciences', the 'useful lifespan of any

\footnotetext{
25 Ibid.

26 Church, G. 2004, A Synthetic Biohazard Nonproliferation Proposal, <http://arep.med.harvard.edu/SBP/ Church_Biohazard04c.htm>.

27 Poste, G. 2004, 'Synthetic biology: charting rational public policies for the oversight and regulation of vanguard technologies', 11 June, <http://openwetware.org/images/3/3a/SB1.0_George.Poste.pdf>.

28 See <http://syntheticbiology.org/SB2.0/Biosecurity_and_Biosafety.html $>$.

29 See Maurer, S. M., Lucas, K. V. and Terrell, S. 2006, From Understanding to Action: Community-Based Options for Improving Safety and Security in Synthetic Biology, Goldman School of Public Policy, University of California, Berkeley, Draft 1.1, <http://gspp.berkeley.edu/iths/UC White Paper.pdf $>$.

30 National Research Council 2006, Globalization, Biosecurity, and the Future of the Life Sciences. Committee on Advances in Technology and the Prevention of their Application to Next Generation Biowarfare Threats, The National Academies Press, Washington, DC, <www.nap.edu/catalog.php?record_id=11567>.
} 
such list would be measured in months, not years' ${ }^{31}$ To emphasise this point, the report pointed out that '[n]ew, unexpected discoveries and applications in RNAi and synthetic biology arose even during the course of deliberations by this Committee'.$^{32}$ Instead, the committee developed a classification scheme for science and technology (S\&T) advances with four different groups. These four groups are

1. technologies that seek to acquire novel biological or molecular diversity

2. technologies that seek to generate novel but predetermined and specific biological or molecular entities through directed design

3. technologies that seek to understand and manipulate biological systems in a more comprehensive and effective manner

4. technologies that seek to enhance production, delivery and 'packaging' of biologically active materials. ${ }^{33}$

Synthetic biology is explicitly mentioned by the committee in relation to the first two of these categories. A concise discussion of the future applications of synthetic biology in the report acknowledges that 'DNA synthesis technology could allow for the efficient, rapid synthesis of viral and other pathogen genomes - either for the purposes of vaccine or therapeutic research and development, or for malevolent purposes or with unintended consequences' ${ }^{34}$ It is thus fair to conclude that the biosecurity community during the deliberations of the Lemon-Relman Committee had clearly identified synthetic biology, albeit with an emphasis on DNA synthesis and not the four subfields of synthetic biology outlined above, as one of the technologies that will have a major impact on the future biothreat spectrum.

This emphasis on DNA synthesis is also reflected in the approach of the National Science Advisory Board on Biosecurity (NSABB). ${ }^{35}$ In order to conduct its work, NSABB can set up working groups to address specific issues including one in the field of synthetic biology. In the first phase of its work, the NSABB synthetic biology working group has sought to address biosecurity implications of the de novo synthesis of select agents. ${ }^{36}$ A report of the synthetic biology working group on this issue was discussed during a NSABB meeting in October 2006

\footnotetext{
31 Ibid., p. 3.

32 Ibid., p. 103.

33 Ibid., p. 3.

34 Ibid., p. 109.

35 National Science Advisory Board for Biosecurity (NSABB) 2006, Addressing Biosecurity Concerns Related to the Synthesis of Select Agents, National Science Advisory Board for Biosecurity, Washington, DC, <http:// oba.od.nih.gov/biosecurity/pdf/Final_NSABB_Report_on_Synthetic_Genomics.pdf $>$.

36 Select agents are those biological agents and toxins that can pose a severe threat to public, animal or plant health, or to animal or plant products. For the current list of select agents, see <http://www.cdc.gov/od/sap/ docs/salist.pdf $>$.
} 
and has subsequently been submitted to the US Government. Clearly, here as well the focus of the threat assessment had not been on engineered bioparts and modules, but on improved DNA-synthesis capabilities as they relate to select agents. Thus, although it is reasonable to assume that since the end of 2006 US policymakers have been aware of the potential biosecurity risks of synthetic biology, discussion of these risks has up to now been limited to only a part of the range of approaches subsumed under the synthetic biology label.

\section{Evolving dual-use potential}

Although the main focus of synthetic biologists is on the design and engineering aspects of this new field of scientific inquiry, some also emphasise the field's contribution to 'achieving a better understanding of life processes' ${ }^{37}$ Clearly, this better understanding is sought in order to improve the human condition via improved diagnostics, therapeutics and other beneficial applications; however, as one study has pointed out, a better understanding of life processes in relation to regulatory systems in the human body also opens new doors for potential misuse of biologically active chemical compounds that can target the human nervous, immune or endocrine systems with a higher degree of specificity. ${ }^{38}$ To the extent that synthesised bioparts, devices and modules are utilised for such misuse, synthetic biology's dual-use potential will represent an incremental change in the misuse potential of the life sciences in general. In principle, however, synthetic biology has a much more profound dual-use potential. If the standardisation of parts and modules progresses to a point where these are truly compatible and, in addition, can be inserted in a robust chassis for application/ dissemination, a threshold in dual-use potential will be crossed. Given the early stage of development at which parts-based synthetic biology finds itself, and the issues related to standardisation referred to above, and more generally the fact that most of synthetic biology lies at the cutting edge of today's life-science research, the progress made by synthetic biologists is most likely to be misused first in an offensive state-level biological weapons (BW) program.

This will change, however, as the dissemination of the knowledge and hands-on experience with synthetic bioparts and modules continue. The already mentioned deskilling efforts by some leading synthetic biologists go hand in hand with the dissemination of do-it-yourself synthetic biology kits and 'how to' protocols. In addition to these, the iGEM competition also supports this trend. Its 'broader goals include: to enable the systematic engineering of biology; to promote the open and transparent development of tools for engineering biology and to help

37 Synthetic Biology in Europe, TESSY Information leaflet, <www.tessy-europe.eu/public-docs/ SyntheticBiology_TESSY-Infomation-Leaflet.pdf>.

38 See Kelle, A., Nixdorff, K. and Dando, M. 2006, Controlling Biochemical Weapons: Adapting Multilateral Arms Control for the 21st Century, Palgrave, Basingstoke, UK, esp. chs 4-6. 
construct a society that can productively apply biological technology'. ${ }^{39}$ Thus, over time, the amount of specialist knowledge that is limited to (relatively) few 'experts' will become increasingly smaller, thereby increasing the likelihood that sub-state actors and individuals will utilise synthetic bioparts and modules for nefarious purposes.

\section{Governance proposals for synthetic biology}

From the formative days of contemporary synthetic biology, addressing the question of governance mechanisms and their relative utility has been a feature of the unfolding discourse on the discipline's societal implications. This early engagement of the scientific community with the risks associated with synthetic biology can in part be traced back to earlier debates about the ethical, legal and social implications of genetic engineering.

As briefly mentioned above, one of the earliest proposals to address synthetic biology's dual-use implications was put forward by George Church in his 'Synthetic Biohazard Non-Proliferation Proposal'. In it he advocated developing a system for both 'instrument and reagent licensing', and to screen for select agents, including a 'DNA agent clearinghouse'. ${ }^{40}$

While Church's proposal foresaw some form of government involvement or oversight in both these systems, subsequent governance proposals placed more emphasis on the self-governance efforts of the scientific community and commercial DNA-synthesis providers.

Such proposals were discussed at the SB2.0 conference, which took place in Berkeley, in May 2006, and during which a full day was devoted to discussion of societal issues surrounding synthetic biology. ${ }^{41}$ The subsequently formulated declaration of the conference contains four resolutions that aim at addressing some of the dual-use implications of synthetic biology - in particular, DNA synthesis that may give rise to safety or security concerns. ${ }^{42}$ The focus on DNA synthesis is also reflected in two of the four resolutions contained in the final declaration. These resolutions support the

development of improved software tools that can be used to check DNA synthesis orders for DNA sequences encoding hazardous biological systems ...

\footnotetext{
$39<$ http://parts2.mit.edu/wiki/index.php/About_iGEM $>$.

40 The proposal is available at <http://arep.med.harvard.edu/SBP/Church_Biohazard04c.htm $>$.

41 Much of the debate was informed by the white paper produced by Maurer and colleagues mentioned above.

42 See the revised public draft of the SB2.0 declaration at $<$ https://dspace.mit.edu/handle/1721.1/18185 $>$.
} 
[A]doption of best-practice sequence checking technology, including customer and order validation, by all commercial DNA synthesis companies ...

[O]ngoing and future discussions within international science and engineering research communities for the purpose of developing creative solutions and frameworks that directly address challenges arising from the ongoing advances in biological technology, in particular, challenges to biological security and biological justice ...

[O]ngoing and future discussions with all stakeholders for the purpose of developing and analyzing governance options ... such that the development and application of biological technology remains overwhelmingly constructive. ${ }^{43}$

In terms of practical next steps to be pursued, the declaration announces the formation of an open working group in support of the improvement of existing software tools for checking DNA sequences, as well as the completion of a study to 'develop policy options that might be used to govern DNA synthesis technology'. ${ }^{44}$

This study, which was conducted jointly by the MIT, the J. Craig Venter Institute and the CSIS, supported the trend to focus governance options in relation to synthetic biology on DNA-synthesis technology. The report's authors identify DNA synthesis itself, as conducted by gene-synthesis firms and oligonucleotide manufacturers, and with the help of DNA synthesisers, as the most effective intervention point for preventing the misuse of synthetic genomics. The authors of the report concluded that for both gene foundries and oligo manufacturers, a combination of screening orders by companies and the certification of orders by a biosafety/biosecurity officer provide the greatest benefits in terms of preventing incidents. The storage of order information by firms was regarded as the most useful tool for responding after an incident had occurred. Lastly, concerning equipment such as DNA synthesisers, the report concluded that the licensing of both equipment and reagents was most likely to enhance biosecurity by preventing misuse. ${ }^{45}$

Ideas developed in this report were subsequently taken up in proposals by the (then existing) two industry associations in the area of synthetic biology. The first of these groups, the International Consortium for Polynucleotide Synthesis (ICPS), put forward a 'tiered DNA synthesis order screening process' ${ }^{46}$ This

\footnotetext{
43 Ibid., p. 3.

44 Ibid.

45 Garfinkel, M. S., Endy, D., Epstein, G. L. and Friedman, R. M. 2007, Synthetic Genomics. Options for Governance, $<$ http://www.csis.org/media/csis/pubs/071017_synthetic_genomics_options.pdf $>$.

46 Bügl, H. et al. 2007, 'DNA synthesis and biological security', Nature Biotechnology, vol. 25, pp. 627-9.
} 
proposal would put DNA-synthesis companies and their industry association at the centre of a governance structure that would, however, not be a selfcontained system of oversight, but rather rely on 'agreed-upon guidelines'. Such guidelines would be operationalised, inter alia, through lists of 'select agents or sequences' that would determine whether and how to process DNAsynthesis orders on the part of those companies that follow the guidelines.

Members of the Industry Association Synthetic Biology (IASB) have focused on a number of interrelated issues that also revolve around the screening of DNA orders by synthesis companies. These were formulated during a workshop that was held in Munich in April 2008 on 'Technical Solutions for Biosecurity in Synthetic Biology' ${ }^{47}$ Motivated by 'our responsibility for the scientific field to which we provide services and products', ${ }^{48}$ workshop participants agreed on the adoption of five distinct work packages

1. harmonisation of screening strategies for DNA-synthesis orders

2. creation of a central virulence-factor database

3. publication of an article on the status quo of synthetic biology

4. establishment of a technical biosecurity working group with members from both organisations in order to 'discuss improvements and next steps for biosecurity measures'

5. formulation of a code of conduct. ${ }^{49}$

With this last work package, the IASB started to expand its activities away from the technically focused measures into the political arena of setting standards and promoting best practices.

The focus of proposals put forward has been on the bottleneck of long-strand DNA synthesis, which has evolved into one of the key enabling technologies for parts and module-based synthetic biology. Some of these proposals place a higher emphasis on government involvement than others, but all try to minimise the negative impact governance might have on scientific progress and economic benefits. By focusing on DNA synthesis these governance measures have in a sense targeted the most developed part of the supply chain for the synthesis of bioparts or modules, whose ancestors can be traced back to the advent of recombinant DNA technology three decades ago, and which is relatively easily targetable by traditional supply-side controls.

47 Industry Association Synthetic Biology n.d., Report on the Workshop 'Technical Solutions for Biosecurity in Synthetic Biology', <http://www.ia-sb.eu>.

48 Ibid., p. 2.

49 Ibid., p. 16. 
In contrast, the notion of making a library of bioparts and modules the object of dual-use informed governance measures has yet to receive substantial attention. It seems that in this context more thought has been devoted to issues of open source versus intellectual property rights (IPR), with large biotechnology companies increasingly discovering synthetic biology for commercial purposes. ${ }^{50}$ Unless a systematic discourse on dual-use governance structures for parts-based and the other synthetic biology subfields identified above will commence soon, it could thus be pre-empted by the IPR-driven attempts to formulate governance solutions. This could also complicate the realisation of any bioethically informed dual-use governance approach for synthetic biology that might be developed out of the approaches and deliberations discussed in the next section.

\section{Bioethical analyses to address the dual-use aspects of synthetic biology}

One of the earliest ethical commentaries on synthetic biology was published in 1999 in Science ${ }^{51}$ and has been regularly quoted by practitioners in the field and observers alike. It acknowledged that in order to 'ensure responsible use of knowledge that could be applied to the construction of biological weapons, we need to give serious thought to monitoring and regulation at the level of national and international public policy' ${ }^{52}$

Yet, as Yearley has concluded a decade later, while Cho and her colleagues 'highlight things that people may have ethical concerns about, the paper does not set out or determine what the ethical analysis might conclude'. ${ }^{53}$ More fundamentally, Yearley's review of bioethics as a template to conduct an ethical review of synthetic biology leads him to caution that this might actually be 'counterproductive since the apparatus constructed to conduct the social and ethical review will come to look like a mere legitimatory cloak for synthetic biology's advance'. ${ }^{54}$ Yet, Yearley remains somewhat elusive in specifying what else might serve as a suitable foundation for an ethical review of synthetic biology.

50 Oye, K. A. and Wellhausen, R. 2009, 'The intellectual commons and property in synthetic biology', in Schmidt et al., op. cit., pp. 121-40.

51 Cho, M. K., Magnus, D., Caplan, A. L., McGee, D. and the Ethics of Genomics Group 1999, 'Ethical considerations in synthesizing a minimal genome', Science, vol. 286, pp. 2087, 2089-90.

52 Ibid., p. 2089.

53 Yearley, S. 2007, 'Review: the ethical landscape: identifying the right way to think about the ethical and societal aspects of synthetic biology research and products', Journal of the Royal Society Interface, $<$ doi:10.1098/rsif.2009.0055.focus >, p. 3.

54 Ibid., p. 6. 
Miller and Selgelid, in contrast, provide a much more detailed and in-depth 'ethical and philosophical consideration' of dual-use issues in the life sciences. ${ }^{55}$ Although not specifically targeted at synthetic biology, their analysis illuminates many aspects of bioethical reasoning that are of relevance to synthetic biology too. Based on 'a particularly morally problematic species of the dual-use dilemma', ${ }^{56}$ in the form of a number of experiments of concern, they discuss the permissibility of certain kinds of research, debate dissemination of dualuse research results, and analyse different ethically informed governance models with which to tackle the dual-use issues presented by the biological sciences. With regard to this last aspect, Miller and Selgelid discard both the laissez-faire option of giving the individual scientist complete autonomy over their research with dual-use potential and the rather draconian option of complete governmental control. Instead they argue for either a mixed system of institutional and governmental controls or a governance approach that would rely on an independent authority being set up. ${ }^{57}$ Thus, while providing a detailed discussion of ethical issues in relation to dual-use life-sciences research, and a narrowing of - in their view - suitable governance options, the analysis remains in this latter dimension somewhat inconclusive.

In contrast with Miller and Selgelid, Ehni's discussion of the ethical responsibilities of scientists engaged in dual-use research is more limited in scope. ${ }^{58} \mathrm{He}$ approaches the issue by discussing the 'basic conflict between the freedom of science and the duty to avoid causing harm' from two perspectivesthat of 'moral skepticism and the ethics of responsibility by Hans Jonas'.$^{59} \mathrm{On}$ this basis, Ehni evaluates

four basic duties ... to define the prospective responsibility of scientists: 1) stopping research in some cases, 2) systematically exploring dangers of dual use in some cases, 3) informing public authorities about possible dangers resulting from research and the application of its results, and 4) not publishing results and descriptions of research results and possible dual-use applications. ${ }^{60}$

Given the nature of the dual-use issues at hand and the way science is organised, Ehni concludes along the lines of Miller and Selgelid that '[i]t is no solution to

55 Miller, S. and Selgelid, M. J. 2007, 'Ethical and philosophical considerations in the dual-use dilemma in the biological sciences', Science and Engineering Ethics, vol. 13, pp. 523-80.

56 Ibid., p. 531.

57 Ibid., p. 573.

58 Ehni, H.-J. 2008, 'Dual use and the ethical responsibility of scientists', Archivum Immunologiae Et

Therapiae Experimentalis, vol. 56, pp. 147-52.

59 Ibid., p. 147.

60 Ibid., p. 151. 
the "dual-use" problem to transfer total responsibility to individuals' ${ }^{61}$ Instead he advocates a 'mixed authority' for the governance of dual-use issues, the details of which he also leaves unspecified.

While the recommendation of not assigning sole responsibility to individual scientists is shared by Kuhlau et al., they point out that the moral duty to prevent harm on the part of an individual researcher does exist and includes both intentional and unintentional harms. ${ }^{62}$ Furthermore, such moral duty linked to the professional role of the researcher carries with it a requirement for an 'awareness of relevant regulation and potential dangers' ${ }^{63}$ This awareness in turn 'entails a continuous process of reviewing one's work in a wider context' ${ }^{64}$ Based on this reasoning, they identify five criteria for the obligation to prevent harm.

In order to take social responsibility and due care, life scientists should strive to prevent harm that is: Within their professional responsibility ... Within their professional capacity and ability ... Reasonably foreseeable ... Proportionally greater than the benefits ... [and] Not more easily achieved by other means. ${ }^{65}$

Kuhlau et al. subsequently apply these criteria to a number of proposed obligations for life scientists in relation to dual-use issues. They conclude that scientific responsibility 'does not involve preventing the act of misuse but rather involves obligations concerned with preventing foreseeable and highly probable harm' (emphasis in original) ${ }^{66}$ Such reasonable obligations include, in their view, the duties to consider negative research implications, to protect sensitive material, technology and knowledge from unauthorised access, and to report suspicious activities. ${ }^{67}$ While this again represents a useful clarification of the obligation of life scientists including synthetic biologists in relation to dual-use issues they face in their work, it leaves both the institutional and the wider governance contexts unexplored within which these duties need to be considered.

The European Group on Ethics (EGE) in Science and New Technologies to the European Commission in its Opinion No. 25 on the 'Ethics of synthetic biology' usefully points out in this respect that '[g]overnance is an overarching concept

\footnotetext{
61 Ibid.

62 Kuhlau, F., Erikson, S., Evers, K. and Höglund, A. T. 2008, 'Taking due care: moral obligations in dual use research', Bioethics, vol. 22, pp. 477-87.

63 Ibid., p. 481.

64 Ibid.

65 Ibid., p. $481 \mathrm{ff}$.

66 Ibid., p. 487.

67 Ibid.
} 
including legal, political and ethical considerations. Since synthetic biology may result in major changes of traditional biology, governance needs to be reflected on all these levels, finally entering the legal sphere. ${ }^{68}$

With respect to ethical consideration of synthetic biology, the EGE distinguishes between conceptual and specific issues, and addresses both biosafety and biosecurity under the latter heading. ${ }^{69}$ In its discussion of potential steps to be taken, the EGE opinion states under the heading of 'Biosecurity, prevention of bioterrorism and dual uses' that '[e]thical analysis must assess the balance between security and transparency', ${ }^{70}$ and moves on to recommend that 'ethical issues that arise because of the potential for dual use should be dealt with at the educational level. Fostering individual and institutional responsibility through ethics discussion on synthetic biology is a key issue'.$^{71}$

In addition, the EGE opinion contains three formal recommendations: 1) linking dual-use bioethics to the Biological Weapons Convention (BWC) by recommending that this international treaty 'should incorporate provisions on the limitation or prohibition of research in synthetic biology'; 2) requesting the European Commission to define a 'comprehensive security and ethics framework for synthetic biology'; and 3) requesting the establishment of DNA-sequence databases with supporting, legally based rules and procedures. ${ }^{72}$

A similarly wide-ranging attempt to chart the ethical issues surrounding synthetic biology was undertaken by the US Presidential Commission for the Study of Bioethical Issues (PCSBI), which in December 2010 produced its first report, entitled New Directions: The Ethics of Synthetic Biology and Emerging Technologies. ${ }^{73}$ Guided by five ethical principles - that is, '(1) public beneficence, (2) responsible stewardship, (3) intellectual freedom and responsibility, (4) democratic deliberation, and (5) justice and fairness ${ }^{74}$ - the report arrives at 18 recommendations, some of which are informed by the dual-use character of synthetic biology or seek to address its implications. Of particular relevance in this context are recommendations 12 and 13. Acknowledging the dynamic character of the field and the resulting changes in dual-use issues of relevance, the committee recommends periodic assessments of safety and security risks be undertaken. It states:

\footnotetext{
68 European Group on Ethics 2009, Ethics of Synthetic Biology, Opinion No. 25, European Union, Brussels, p. 36.

73 Presidential Commission for the Study of Bioethical Issues (PCSBI) 2010, New Directions: The Ethics of Synthetic Biology and Emerging Technologies, Presidential Commission for the Study of Bioethical Issues, Washington, DC.

74 Ibid., p. 5.
} 
Risks to security and safety can vary depending on the setting in which research occurs. Activities in institutional settings, may, though certainly do not always, pose lower risks than those in non-institutional settings. At this time, the risks posed by synthetic biology activities in both settings appear to be appropriately managed. As the field progresses, however, the government should continue to assess specific security and safety risks of synthetic biology research activities in both institutional and non-institutional settings including, but not limited to, the 'do-ityourself' community ... An initial review should be completed within 18 months and the results made public to the extent permitted by law. ${ }^{75}$

In case this review identifies 'significant unmanaged security or safety concerns', recommendation 13 foresees changes to existing oversight and control mechanisms with a view to 'making compliance with certain oversight or reporting measures mandatory for all researchers ... regardless of funding sources' ${ }^{76}$ This last point would lead to a significant tightening of existing oversight mechanisms as it would expand their reach beyond publicly funded life-science research and oblige commercial research activities to abide by the same regulatory framework.

\section{Conclusions}

This chapter set out to first illustrate that synthetic biology is one of the most dynamic new subfields of the life sciences. It offers the potential to live up to the promise that the discipline behind the label of genetic engineering has long aspired to: the engineering of biological parts, devices and systems, either to modify existing or to create new ones. By applying the toolbox of engineering disciplines and information technology to biology, a wide range of potential applications becomes possible, ranging across scientific and engineering disciplines. Some of the anticipated benefits of synthetic biology, such as the development of low-cost drugs or the production of chemicals and energy by engineered bacteria, are potentially very significant. There are, however, also significant risks due to deliberate or accidental damage. In a way, synthetic biology can be described as the prototypical emerging dual-use technoscience.

Although first attempts at formulating governance mechanisms can be identified, these are for the most part focusing only on a subfield, or, as some would say, enabling technology, of synthetic biology - that is, large-scale commercial DNA synthesis. The conceptualisation of dual-use governance processes and structures for the bioparts and modules-based approach within synthetic 
biology is, by contrast, still in its infancy (as is the case for the other subfields outlined above). Academic work on the characteristics of dual-use issues from an (bio-)ethical perspective has increased in numbers over recent years, but stops short of considering embedding their analysis and recommendations into the wider institutional or political context that synthetic biologists find themselves in. Similarly, the opinions and recommendations of advisory bodies and committees briefly discussed are quite generic and deal with dual-use issues among many other ethical questions raised by synthetic biology.

What are required are thus more detailed analyses of the dual-use implications of the whole of synthetic biology and systematic dual-use bioethics awarenessraising efforts that reach all practising synthetic biologists and that are supplemented by education and training efforts as well as the formulation of codes and other governance tools that go well beyond the rather technically orientated order screening by DNA-synthesis companies. 